\title{
Decentralized clearing in financial networks
}

Citation for published version (APA):

Csóka, P., \& Herings, P. J. J. (2016). Decentralized clearing in financial networks. Maastricht University, Graduate School of Business and Economics. GSBE Research Memoranda No. 005 https://doi.org/10.26481/umagsb.2016005

Document status and date:

Published: 01/01/2016

DOI:

10.26481/umagsb.2016005

Document Version:

Publisher's PDF, also known as Version of record

\section{Please check the document version of this publication:}

- A submitted manuscript is the version of the article upon submission and before peer-review. There can be important differences between the submitted version and the official published version of record.

People interested in the research are advised to contact the author for the final version of the publication, or visit the DOI to the publisher's website.

- The final author version and the galley proof are versions of the publication after peer review.

- The final published version features the final layout of the paper including the volume, issue and page numbers.

Link to publication

\footnotetext{
General rights rights.

- You may freely distribute the URL identifying the publication in the public portal. please follow below link for the End User Agreement:

www.umlib.nl/taverne-license

Take down policy

If you believe that this document breaches copyright please contact us at:

repository@maastrichtuniversity.nl

providing details and we will investigate your claim.
}

Copyright and moral rights for the publications made accessible in the public portal are retained by the authors and/or other copyright owners and it is a condition of accessing publications that users recognise and abide by the legal requirements associated with these

- Users may download and print one copy of any publication from the public portal for the purpose of private study or research.

- You may not further distribute the material or use it for any profit-making activity or commercial gain

If the publication is distributed under the terms of Article $25 \mathrm{fa}$ of the Dutch Copyright Act, indicated by the "Taverne" license above, 


\section{Maastricht University}

Péter Csóka,

P. Jean-Jacques Herings

Decentralized Clearing in Financial Networks

RM/16/005

\section{GSBE}

Maastricht University School of Business and Economics

Graduate School of Business and Economics

P.O Box 616

NL- 6200 MD Maastricht

The Netherlands 


\title{
Decentralized Clearing in Financial Networks*
}

\author{
Péter Csóka ${ }^{\dagger} \quad$ P. Jean-Jacques Herings ${ }^{\ddagger}$ \\ January 14, 2016
}

\begin{abstract}
We consider a situation in which agents have mutual claims on each other, summarized in a liability matrix. Agents' assets might be insufficient to satisfy their liabilities leading to defaults. We assume the primitives to be denoted in some unit of account. In case of default, bankruptcy rules are used to specify the way agents are going to be rationed. We present a convenient representation of bankruptcy rules.

A clearing payment matrix is a payment matrix consistent with the prevailing bankruptcy rules that satisfies limited liability and priority of creditors. Both clearing payment matrices and the corresponding values of equity are not uniquely determined. We provide bounds on the possible levels equity can take. We analyze decentralized clearing processes and show the convergence of any such process in finitely many steps to the least clearing payment matrix. When the unit of account is sufficiently small, all decentralized clearing processes lead essentially to the same value of equity as a centralized clearing procedure. As a policy implication, it is not necessary to collect and process all the sensitive data of all the agents simultaneously and run a centralized clearing procedure.
\end{abstract}

Keywords: Networks, Bankruptcy Problems, Systemic Risk, Decentralized Clearing, Indivisibilities.

JEL Classification: C71, G10.

${ }^{*}$ We would like to thank Péter Benczúr, Péter Biró, Dávid Csercsik, Miklós Pintér, Adam Zawadowski and participants of East Asian Conference on Game Theory, Corvinus Game Theory Seminar, 6th Annual Financial Market Liquidity Conference and 10th Workshop on Economic Design and Institutions for helpful comments.

†Corvinus University of Budapest, Corvinus Business School, Department of Finance and "Momentum" Game Theory Research Group, Centre for Economic and Regional Studies, Hungarian Academy of Sciences. E-mail: peter.csoka@uni-corvinus.hu. Péter Csóka thanks funding from National Research, Development and Innovation Office (NKFIH, PD 105859), from HAS (LP-004/2010) and from COST Action IC1205 on Computational Social Choice.

${ }_{\ddagger}^{\ddagger}$ Department of Economics, Maastricht university, P.O. Box 616, 6200 MD, Maastricht, The Netherlands. E-mail: P.Herings@maastrichtuniversity.nl. 


\section{Introduction}

The treatment of bankruptcy of countries, banks, firms, organizations, and individuals will always be a challenge for society. In the original bankruptcy problem, starting with the seminal paper of O'Neill (1982), there is a single bankrupt agent and the other agents only have claims on the estate of this agent. In this paper, we analyze networks of agents, where agents have mutual claims on each other. An agent is characterized by his endowments and his liabilities towards the other agents. The assets of an agent consist of his endowments together with the liabilities of other agents towards him. If the assets of an agent are not sufficient to satisfy his own liabilities, then the agent has to default. In a network setting, a default can also result from contagion, where an agent defaults only because other agents are not fully paying their liabilities to him. The default of a single agent can therefore result in domino effect that potentially leads to an all encompassing cascade of defaults. We are interested in the final resulting outcome in terms of payments and equity and how this outcome is influenced by the use of centralized procedures versus decentralized clearing processes.

An important application concerns financial networks, where Eisenberg and Noe (2001) is the seminal paper. Recent crisis on financial markets triggered by the Lehman bankruptcy as well as sovereign debt problems of European countries provide prime examples of why the network perspective is important. Part of the literature on financial networks concerns the appropriate measurement of systemic risk, see Chen et al. (2013) for an axiomatic approach as well as Demange (2015). There is also a substantial literature that relates the number and magnitude of defaults to the network topology and that characterizes those structures that tend to propagate default, see Gai and Kapadia (2010), Elliott et al. (2014), Acemoglu et al. (2015), Capponi et al. (2015), and Glasserman and Young (2015). The basic setup of Eisenberg and Noe (2001) has also been extended in various directions, for instance in Cifuentes et al. (2005) and Shin (2008) by allowing for liquidity considerations or in Rogers and Veraart (2013) by allowing for costs of default.

Network effects of defaults occur also outside financial settings. Brown (1979) presents an application of a supply chain network consisting of coal mines and power companies, where due to a strike only the non-union mines produce and the other mines default on their deliveries of coal. Another example is related to international student exchange problems, as well as the closely related problem of tuition exchange studied in Dur and Ünver (2015), where the agents correspond to colleges. The endowments of a college equal the maximum net inflow of students it can handle, its liabilities correspond to commitments made to receive incoming students, and claims are the agreements with other colleges to send outgoing students. As another example, the agents can be servers that process jobs

for a set of users. The endowments of a server correspond to its capacity for processing 
jobs, its liabilities to jobs that it has to process for other servers, and its claims to jobs that are outsourced to other servers. An example similar to the one with servers concerns time banks, where the agents are workers instead of servers.

In reality, endowments and claims are denoted in some smallest unit of account (dollars, number of students, number of jobs, etc.). We therefore analyze the discrete setup, where endowments and liabilities are expressed as non-negative integers. The discrete setup has also been analyzed in the bankruptcy literature with multiple claimants on a single estate, see Moulin (2000), Moulin and Stong (2002), Herrero and Martínez (2008), and Chen (2015), but so far not in a network setting. Given the prominence of the financial applications, we use the terminology of that framework, but want to emphasize that our model is relevant outside that specific setup.

If an agent is bankrupt, then a division rule specifies how the liabilities of various creditors are going to be settled. Following the seminal paper by Eisenberg and Noe (2001), the literature on systemic risk in financial networks has adopted proportional rules specifying payment ratios less than one in case of default. In reality, not all the liabilities are of the same seniority and some of the liabilities are more senior than others. American bankruptcy law, for instance, is a mixed lexicographic-proportional system, see Kaminski (2000). We therefore allow for general bankruptcy rules. We relate division rules as used in the divisible setup to bankruptcy rules as used in our discrete framework and present a convenient representation for bankruptcy rules.

A payment matrix describes how much agents actually pay to each other. We introduce the notions of feasibility, limited liability, and priority of creditors and define the notion of a clearing payment matrix. Feasibility of a payment matrix means that payments are made in accordance with bankruptcy rules. Limited liability means the payment matrix should result in non-negative equity levels for all agents. Priority of creditors requires that if an agent is not paying all of its liabilities, then a higher payment should lead to a negative equity level. Contrary to the divisible case, where Eisenberg and Noe (2001) formulate the property of absolute priority, our notion of priority of creditors sometimes allows an agent to have positive equity even if some outstanding liabilities remain.

We characterize all clearing payment matrices as a fixed point of an appropriately defined function. We show that there exist a least and a greatest clearing payment matrix. Unlike the divisible case, different clearing payment matrices may result in different amounts of equity. We give a formula for the minimal and maximal difference between the value of equity for a given agent in any two clearing payment matrices.

The literature on financial networks has presented a number of algorithms to compute a clearing payment matrix with a typical emphasis on the computation of the greatest clearing payment matrix. Examples of such algorithms are presented in Eisenberg and Noe 
(2001), Rogers and Veraart (2013), and Elliott et al. (2014). These algorithms correspond to centralized procedures for finding a clearing payment matrix. The required levels of payments during the execution of the algorithm are typically not implementable and are computed by solving a joint optimization program or a simultaneous system of equations.

As noted in Elsinger et al. (2006) and Gai and Kapadia (2010), the complexity of the financial system means that policymakers have only partial information about the true linkages between financial intermediaries. It is therefore not realistic to assume that a single decision maker has all the information that is needed in the execution of the algorithms. On top of that, it is not realistic to assume that all assets of defaulting agents can be liquidated instantaneously. We therefore look at decentralized processes to arrive at a clearing payment matrix.

By decentralized we mean a process where agents are making payments one by one rather than simultaneous, where only local information is needed to determine the amounts to be paid, and where the payments made are implementable at each iteration of the process. We show that any decentralized process in a large class converges in finitely many iterations to the least clearing payment matrix. In this sense, the cost of decentralization is therefore to go from the greatest to the least clearing payment matrix. The bounds we derive on the final levels of equity show that this cost is typically small in financial markets. Thus as a policy implication for financial markets, instead of working on collecting and processing data centrally, we suggest that it is sufficient to have local liquidators enforcing bankruptcy rules.

This paper is organized as follows. Section 2 presents division rules and bankruptcy rules, used in the divisible and the discrete setup respectively, for problems with a single estate and multiple claimants. Section 3 extends bankruptcy rules to the network setup and presents some examples. In Section 4 we analyze clearing payment matrices as fixed points and derive the bounds for the difference between the values of equity for a given agent in any two clearing payment matrices. Section 5 shows how any decentralized clearing process in a large class converges to the least clearing payment matrix. Section 6 deals with the convergence to the divisible case. Section 7 concludes.

\section{Bankruptcy Rules}

A bankruptcy problem is a pair $(c, E) \in \mathbb{R}_{+}^{I} \times \mathbb{R}_{+}$, where $\mathbb{R}_{+}$is the set of non-negative real numbers. In a bankruptcy problem, the amount of the estate $E$ has to be divided among the agents in the set $I$ with cardinality $n$. Agent $i \in I$ has a claim on the estate equal to $c_{i}$. In the bankruptcy literature, it is typically assumed that $\sum_{i \in I} c_{i} \geq E$ and a division rule is defined as a function that associates with each such $(c, E)$ a vector $y \in \mathbb{R}_{+}^{I}$ such 
that $\sum_{i \in I} y_{i}=E$ and $y_{i} \leq c_{i}$ for every $i \in I$. For surveys of the literature on bankruptcy problems, we refer the reader to Thomson (2003), Thomson (2013), and Thomson (2015). ${ }^{1}$ Since we will also encounter situations where the value of the estate surpasses the sum of the claims, we define a division rule as follows.

Definition 2.1. Given a vector of claims $c \in \mathbb{R}_{+}^{I} \backslash\left\{0^{I}\right\}$, a division rule is a monotonic function $d: \mathbb{R}_{+} \rightarrow \mathbb{R}_{+}^{I}$ such that, for every $E \in \mathbb{R}_{+}, \sum_{i \in I} d_{i}(E)=\min \left\{\sum_{i \in I} c_{i}, E\right\}$ and, for every $i \in I, d_{i}(E) \leq c_{i}$.

Definition 2.1 requires division rules to be monotonic: for every $E, E^{\prime} \in \mathbb{R}_{+}$such that $E \leq E^{\prime}$, it holds for every $i \in I$ that $d_{i}(E) \leq d_{i}\left(E^{\prime}\right)$ or, equivalently, $d(E) \leq d\left(E^{\prime}\right)$. A weakly higher value of the estate leads to weakly higher payments to everybody. This property is called resource monotonicity in the bankruptcy literature, see Thomson (2003), or endowment monotonicity, see Thomson (2015). It can be shown that the conditions of Definition 2.1 imply that division rules are continuous.

An important class of division rules are the priority division rules.

Definition 2.2. Given a vector of claims $c \in \mathbb{R}_{+}^{I}$ and a permutation $\pi: I \rightarrow\{1, \ldots, n\}$, the priority division rule $d^{\pi}: \mathbb{R}_{+} \rightarrow \mathbb{R}_{+}^{I}$ is defined by

$$
d_{j}^{\pi}(E)=\max \left\{0, \min \left\{c_{j}, E-\sum_{i \in \pi^{-1}(\{1, \ldots, \pi(j)-1\})} c_{i}\right\}\right\}, \quad j \in I, E \in \mathbb{R}_{+} .
$$

Under the division rule $d^{\pi}$, the estate has a priority list of creditors as determined by the permutation $\pi$. The claims of agents $\pi^{-1}(1), \pi^{-1}(2), \ldots$ are paid for sequentially as long as the estate permits this.

Another frequently used division rule is the proportional division rule.

Definition 2.3. Given a vector of claims $c \in \mathbb{R}_{+}^{I}$, the proportional division rule $d^{\text {prop }}$ : $\mathbb{R}_{+} \rightarrow \mathbb{R}_{+}^{I}$ is defined by

$$
d_{j}^{\text {prop }}(E)=\min \left\{c_{j}, \frac{c_{j}}{\sum_{i \in I} c_{i}} E\right\}, \quad j \in I, E \in \mathbb{R}_{+} .
$$

${ }^{1}$ There is also an emerging literature on the extension of the bankruptcy literature to network settings. The emphasis in these papers is on the axiomatic foundation of allocation rules. Bjørndal and Jörnsten (2009) analyze generalized bankruptcy problems with multiples estates as flow sharing problems and define the nucleolus and the constrained egalitarian solution for such problems. Moulin and Sethuraman (2013) consider bipartite rationing problems, where agents can have claims on a subset of unrelated estates. They consider whether rules for single resource problems can be consistently extended to their framework. Groote Schaarsberg et al. (2013) axiomatize the Aumann-Maschler bankruptcy rule in financial networks with general division rules. 
Under the proportional division rule, the estate is divided in proportion to the claims. If the estate exceeds the sum of the claims, then every claimant receives his claim.

It is standard in both the bankruptcy and the systemic risk literature to assume that the estate is arbitrarily divisible. Estates and claims are real numbers and so is the amount paid as determined by a division rule. In reality, estates and claims are denoted in some smallest unit of account and are therefore non-negative integers. For papers in the bankruptcy literature, the discrete setup has also been studied in Young (1994), Moulin (2000), Moulin and Stong (2002), Herrero and Martínez (2008), and Chen (2015). The emphasis in these papers is on the axiomatic foundation of allocation rules. All papers in the systemic risk literature stick to the divisible approach.

When taking the integer requirement into account, we will refer to bankruptcy rules rather than division rules. It is evident how to define the priority bankruptcy rule, since priority division rules applied to integer-valued estates and claims lead to integer valued payments. However, it is easy to see that the proportional division rule is not necessarily leading to integers, even if the estate and the claims are. It is for this reason that Moulin (2000) describes the priority rules as the most natural rationing methods in the discrete model. Our desire to allow for a discrete version of for instance the proportional division rule motivates the following definition of a bankruptcy rule. Let $\mathbb{N}_{0}$ denote the natural numbers including 0.

Definition 2.4. Given a vector of claims $c \in \mathbb{N}_{0}^{I}$, a bankruptcy rule is a monotonic function $b: \mathbb{N}_{0} \rightarrow \mathbb{N}_{0}^{I}$ such that, for every $E \in \mathbb{N}_{0}, \sum_{i \in I} b_{i}(E) \leq \min \left\{\sum_{i \in I} c_{i}, E\right\}$ with equality when $\sum_{i \in I} c_{i} \leq E$ and, for every $i \in I, b_{i}(E) \leq c_{i}$. Moreover, for every $E, E^{\prime} \in \mathbb{N}_{0}$ such that $E \leq E^{\prime}, \sum_{i \in I} b_{i}\left(E^{\prime}\right) \leq E$ implies $b(E)=b\left(E^{\prime}\right)$.

We illustrate the definition of bankruptcy rules in Example 2.8. Contrary to division rules, the assumptions made on bankruptcy rules allow for the possibility that $\sum_{i \in I} b_{i}(E)<$ $E$ if $E<\sum_{i \in I} c_{i}$. Some of the estate may not be distributed among the agents in case the estate falls below the total value of the liabilities. However, the requirement that for every $E, E^{\prime} \in \mathbb{N}_{0}$ such that $E \leq E^{\prime}, \sum_{i \in I} b_{i}\left(E^{\prime}\right) \leq E$ implies $b\left(E^{\prime}\right)=b(E)$ puts limits on the extent to which paying less than the estate is possible. The bankruptcy literature that has been dealing with the discrete setup has insisted on the requirement that $\sum_{i \in I} b_{i}(E)=E$, thereby ruling out a discrete version of the proportional rule. We therefore allow for a larger class of bankruptcy rules. We now elaborate on this issue and in doing so, we also present a convenient representation for bankruptcy rules.

The image $F(b)$ of a bankruptcy rule $b$ determines the feasible set of payments. More formally, we have

$$
F(b)=b\left(\mathbb{N}_{0}\right)=\cup_{\left\{E \in \mathbb{N}_{0} \mid E \leq \sum_{i \in I} c_{i}\right\}}\{b(E)\} .
$$


The feasible set of payments $F(b)$ can be found by considering the value of the bankruptcy rule for integer values of the estate between zero and the total amount of claims.

The requirement that for every $E, E^{\prime} \in \mathbb{N}_{0}$ such that $E \leq E^{\prime}, \sum_{i \in I} b_{i}\left(E^{\prime}\right) \leq E$ implies $b(E)=b\left(E^{\prime}\right)$ corresponds to the requirement that bankruptcy rules impose maximal feasible payments. Indeed, $b(E)$ is the maximal vector in $F(b)$ for which the sum of the components is less than or equal to $E$. Notice that the monotonicity of $b$ implies that $\leq$ is a total order on the set $F(b)$, i.e. the order $\leq$ on $F(b)$ is antisymmetric, transitive, and complete. A maximal vector in $F(b)$ is therefore uniquely determined.

Vice versa, any bounded set $F \subset \mathbb{N}_{0}^{I}$, which is totally ordered by $\leq$ and contains $0^{I}$, pins down an induced bankruptcy rule $b^{F}$. For $E \in \mathbb{N}_{0}$, let

$$
b^{F}(E)=\max \left\{f \in F \mid \sum_{i \in I} f_{i} \leq E\right\},
$$

where the maximum is unique since $F$ is a finite set, $F$ contains $0^{I}$, and $\leq$ is a total order on $F$. The following proposition states that $b^{F}$ is indeed a bankruptcy rule, where the vector of claims is given by $c=\max F$.

Proposition 2.5. Let $F$ be a bounded subset of $\mathbb{N}_{0}^{I}$, which is totally ordered by $\leq$ and contains $0^{I}$. Then $b^{F}$ is a bankruptcy rule, given the vector of claims $c=\max F$.

Proof. Clearly, it holds that $b^{F}$ is a monotonic function from $\mathbb{N}_{0}$ into $\mathbb{N}_{0}^{I}$. If $\sum_{i \in I} c_{i} \leq E$, then

$$
b^{F}(E)=\max \left\{f \in F \mid \sum_{i \in I} f_{i} \leq E\right\}=\max F=c,
$$

where the second equality follows since $c=\max F$ and $\sum_{i \in I} c_{i} \leq E$. In this case, we therefore have that

$$
\sum_{i \in I} b_{i}^{F}(E)=\min \left\{\sum_{i \in I} c_{i}, E\right\} .
$$

If $\sum_{i \in I} c_{i}>E$, then

$$
\sum_{i \in I} b_{i}^{F}(E) \leq E=\min \left\{\sum_{i \in I} c_{i}, E\right\},
$$

where the inequality follows immediately from the definition of $b^{F}(E)$.

Since $F$ is totally ordered by $\leq$, we have, for every $f \in F, f \leq \max F=c$. It now follows that, for every $E \in \mathbb{N}_{0}$, for every $i \in I, b_{i}^{F}(E) \leq c_{i}$.

Let $E, E^{\prime} \in \mathbb{N}_{0}$ be such that $E \leq E^{\prime}$ and $\sum_{i \in I} b_{i}^{F}\left(E^{\prime}\right) \leq E$. Since $b^{F}\left(E^{\prime}\right)=\max \{f \in$ $\left.F \mid \sum_{i \in I} f_{i} \leq E^{\prime}\right\}$ and $\sum_{i \in I} b_{i}^{F}\left(E^{\prime}\right) \leq E$, it follows that

$$
b^{F}(E)=\max \left\{f \in F \mid \sum_{i \in I} f_{i} \leq E\right\}=b^{F}\left(E^{\prime}\right) .
$$


Each division rule induces a bankruptcy rule in the following way. Given a set $X \subset \mathbb{R}_{+}^{I}$, we define

$$
\lfloor X\rfloor=\left\{f \in \mathbb{N}_{0}^{I} \mid \exists x \in X \text { such that } f=\lfloor x\rfloor\right\},
$$

where $\lfloor x\rfloor$ denotes the vector obtained by taking for every $i \in I$ the floor of $x_{i}$, the largest integer which is less than or equal to $x_{i}$.

Definition 2.6. The division rule $d: \mathbb{R}_{+} \rightarrow \mathbb{R}_{+}^{I}$ leads to the induced bankruptcy rule $b^{\left\lfloor d\left(\mathbb{R}_{+}\right)\right\rfloor}: \mathbb{N}_{0} \rightarrow \mathbb{N}_{0}^{I}$.

The next result establishes that $b^{\left\lfloor d\left(\mathbb{R}_{+}\right)\right\rfloor}$is a bankruptcy rule indeed.

Proposition 2.7. Given a vector of claims $c \in \mathbb{R}_{+}^{I}$, let $d: \mathbb{R}_{+} \rightarrow \mathbb{R}_{+}^{I}$ be a division rule. The function $b^{\left\lfloor d\left(\mathbb{R}_{+}\right)\right\rfloor}: \mathbb{N}_{0} \rightarrow \mathbb{N}_{0}^{I}$ is a bankruptcy rule, given the vector of claims $\lfloor c\rfloor=\max \left\lfloor d\left(\mathbb{R}_{+}\right)\right\rfloor$.

Proof. We show that $\left\lfloor d\left(\mathbb{R}_{+}\right)\right\rfloor$is a bounded subset of $\mathbb{N}_{0}^{I}$ containing $0^{I}$ that is totally ordered by $\leq$. The result then follows from Proposition 2.5.

Since, for every $E \in \mathbb{R}_{+}$, for every $i \in I, d_{i}(E) \leq c_{i}$, it follows that $\left\lfloor d\left(\mathbb{R}_{+}\right)\right\rfloor$is a bounded subset of $\mathbb{N}_{0}^{I}$. Monotonicity of $d$ implies that $\left\lfloor d\left(\mathbb{R}_{+}\right)\right\rfloor$is totally ordered by $\leq$. Since $d$ maps into $\mathbb{R}_{+}^{I}$ and $\sum_{i \in I} d_{i}(0)=\min \left\{\sum_{i \in I} c_{i}, 0\right\}=0$, it follows that $d(0)=0^{I}$, so $0^{I} \in\left\lfloor d\left(\mathbb{R}_{+}\right)\right\rfloor$.

We illustrate the definitions of bankruptcy rule and feasible set of payments in the following example.

Example 2.8. We have three agents $I=\{1,2,3\}$ with estate $E=1$ and claims $c=(0,2,2)$ as presented in Table 1 .

\begin{tabular}{c|ccc}
$E$ & & & $c$ \\
\hline 1 & 0 & 2 & 2
\end{tabular}

Table 1: The estate and claims of the agents in Example 2.8.

First, let us consider priority bankruptcy rules, bankruptcy rules induced by priority division rules. Suppose priorities are described by the identity, $\pi(1)=1, \pi(2)=2$, and $\pi(3)=3$, so first payments to agent 1 should be made, a possible remainder of the estate to agent 2, and if there is still part of the estate remaining, payments can be made to agent 3 . It is easily verified that the feasible set of payments is given by

$$
F=\left\lfloor d^{\pi}\left(\mathbb{R}_{+}\right)\right\rfloor=\{(0,0,0),(0,1,0),(0,2,0),(0,2,1),(0,2,2)\} .
$$


It therefore holds that $b^{F}(1)=(0,1,0)$, so the entire estate goes to agent 2 .

By Proposition 2.7, the priority bankruptcy rules satisfy all the assumptions we have imposed on bankruptcy rules. A priority bankruptcy rule $b$ also has the property that

$\sum_{i \in I} b_{i}(E)=\min \left\{E, \sum_{i \in I} c_{i}\right\}$ for every $E \in \mathbb{N}_{0}$, so the equality also holds in case $\sum_{i \in I} c_{i}>$ $E$. Priority bankruptcy rules have nice axiomatic foundations. As has been demonstrated in Moulin (2000) these are the only rules satisfying consistency, upper composition, and lower composition.

Second, let us consider the proportional bankruptcy rule, the bankruptcy rule induced by the proportional division rule. In this case

$$
F=\left\lfloor d^{\text {prop }}\left(\mathbb{R}_{+}\right)\right\rfloor=\{(0,0,0),(0,1,1),(0,2,2)\} .
$$

It follows that $b^{F}(1)=(0,0,0)$, so no payments are made to any agent in this case.

Again by Proposition 2.7, the proportional bankruptcy rules satisfies all the assumptions we have imposed on bankruptcy rules. A proportional bankruptcy rule $b$ does not have the property that $\sum_{i \in I} b_{i}(E)=\min \left\{E, \sum_{i \in I} c_{i}\right\}$ for all values of $E$ as follows clearly from the example.

As a final example, consider the all or nothing bankruptcy rule, in which either all or none of the claims are being paid. An example of such a rule can be found in Acemoglu et al. (2015) who study banking networks and assume that banks are forced to liquidate their projects in full, e.g. because it is difficult to liquidate a fraction of an ongoing real project. Other examples would arise in applications with supply chain networks, where either a full or no delivery takes place.

In Example 2.8, the feasible set of payments corresponding to the all or nothing bankruptcy rule is given by

$$
F=\{(0,0,0),(0,2,2)\}
$$

The all or nothing bankruptcy rule is an example of a bankruptcy rule that is not induced by any division rule. Indeed, let $d$ be a division rule, given claims $c=(0,2,2)$. Since $d$ is continuous, the set $\left\lfloor d\left(\mathbb{R}_{+}\right)\right\rfloor$contains an element $f$ such that $f_{2}=1$, as well as an element $f^{\prime}$ such that $f_{3}^{\prime}=1$.

The all or nothing bankruptcy rule satisfies all the assumptions we have imposed on bankruptcy rules by Proposition 2.5.

\section{Clearing Payment Matrices}

In the bankruptcy literature, there is typically a single bankrupt agent and the estate is an exogenously given amount. In the systemic risk literature, there are multiple defaulting 
agents and the estates are determined endogenously. In this section, we extend bankruptcy rules to financial networks and define clearing payment matrices.

The primitives of a financial network are given by the tuple $(z, L, b)$.

The vector $z \in \mathbb{N}_{0}^{I}$ represents the endowments of the agents in the set $I$. The endowment of an agent includes all his tangible and intangible assets, but excludes the claims and liabilities such an agent has towards the other agents.

The $n \times n$ liability matrix $L \in \mathbb{N}_{0}^{I \times I}$ describes the mutual claims of the agents. Its entry $L_{i j}$ is the liability of agent $i$ towards agent $j$. We make the normalizing assumption that $L_{i i}=0$ for all $i \in I$. In general, it can occur that agent $i$ has a liability towards agent $j$ and vice versa, so both $L_{i j}>0$ and $L_{j i}>0$.

The payments to be made by agent $i \in I$ to the other agents are determined by the bankruptcy rule $b_{i}: \mathbb{N}_{0} \rightarrow \mathbb{N}_{0}^{I}$. The vector of claims on the estate of agent $i$ is given by $L_{i}$, that is, row $i$ of the liability matrix $L$. Given a value $E_{i} \in \mathbb{N}_{0}$ of the estate of agent $i \in I$, the monetary amount $b_{i j}\left(E_{i}\right) \in \mathbb{N}_{0}$ specifies how much agent $i$ has to pay to agent $j \in I$. The requirement of a bankruptcy rule in Definition 2.4 that $b_{i j}\left(E_{i}\right) \leq L_{i j}$ for every $j \in I$ now implies that the function $b_{i i}$ is identically equal to 0 . The feasible set of payments $F\left(b_{i}\right)$ corresponding to bankruptcy rule $b_{i}$ is denoted by $F_{i}$.

Contrary to the bankruptcy literature, the value of the estate of agent $i$ is endogenous in a financial network, since it depends not only on the initial endowments of agent $i \in I$, but also on the claims $i$ has on other agents, part of which may not be received by agent $i$.

The tuple $\left(b_{i}\right)_{i \in I}$ of bankruptcy rules is denoted by $b$.

An $n \times n$ payment matrix $P \in \mathbb{N}_{0}^{I \times I}$ collects the mutual payments of the agents, that is, $P_{i j}$ is the amount paid by agent $i$ to agent $j$. We make the normalizing assumption that $P_{i i}=0$ for all $i \in I$. The set of all payment matrices with this property is denoted by $\mathcal{M}$. The partial order $\leq$ on $\mathcal{M}$ is defined in the usual way: For $P, P^{\prime} \in \mathcal{M}$, it holds that $P \leq P^{\prime}$ if and only if $P_{i j} \leq P_{i j}^{\prime}$ for all $(i, j) \in I \times I$.

Given a financial network $(z, L, b)$, a payment matrix $P \in \mathcal{M}$ is feasible if for every $i \in I$ it holds that $P_{i} \in F_{i}$. A payment matrix is feasible if every row $i$ of the matrix belongs to the feasible set of payments of agent $i$, that is payments are made in accordance with bankruptcy rules. The set of all feasible payment matrices is denoted by $\mathcal{P}$, so

$$
\mathcal{P}=\left\{P \in \mathcal{M} \mid \forall i \in I, P_{i} \in F_{i}\right\} .
$$

The sum of the initial endowments of an agent and the payments received from the other agents determines an agent's asset value, more formally defined as follows.

Definition 3.1. Given a financial network $(z, L, b)$ and a payment matrix $P \in \mathcal{M}$, the asset value $a_{i}(P)$ of agent $i \in I$ is given by

$$
a_{i}(P)=z_{i}+\sum_{j \in I} P_{j i} .
$$


The asset value of an agent will play the role of the estate.

Subtracting the payments as made by an agent from his asset value yields an agent's equity. More formally, we have the following definition.

Definition 3.2. Given a financial network $(z, L, b)$ and a payment matrix $P \in \mathcal{M}$, the equity $e_{i}(P)$ of agent $i \in I$ is given by

$$
e_{i}(P)=a_{i}(P)-\sum_{j \in I} P_{i j}=z_{i}+\sum_{j \in I}\left(P_{j i}-P_{i j}\right) .
$$

If agent $i \in I$ has negative equity even when all agents pay all their liabilities, so if

$$
e_{i}(L)=z_{i}+\sum_{j \in I}\left(L_{j i}-L_{i j}\right)<0,
$$

then agent $i$ has so-called fundamental default. When an agent defaults only because other agents are not fully paying their liabilities to him, then the agent is said to have contagion default.

It holds that

$$
\sum_{i \in I} e_{i}(P)=\sum_{i \in I} z_{i}+\sum_{i \in I} \sum_{j \in I}\left(P_{j i}-P_{i j}\right)=\sum_{i \in I} z_{i} .
$$

Payment matrices only lead to the redistribution of initial endowments.

Example 3.3. Consider a financial network $(z, L, b)$ with three agents $I=\{1,2,3\}$ and endowments and liabilities as presented in Table 2. For every $i \in I$, the bankruptcy rule $b_{i}$ equals the priority bankruptcy rule $b^{\pi}$ where $\pi$ is the identity, so agent 1 has priority over agent 2 , who in turn has priority over agent 3.

\begin{tabular}{l|lll}
$z$ & & \multicolumn{3}{|c}{$L$} & \\
\hline 1 & 0 & 2 & 2 \\
1 & 2 & 0 & 2 \\
1 & 0 & 0 & 0
\end{tabular}

Table 2: The endowments and liabilities of the agents in Example 3.3.

The payment matrix $P$ in Table 3 is feasible since each row $i$ is selected from the feasible set of payments $F_{i}$. Agent 1 has equity $e_{1}(P)=2$, but still has unpaid liabilities to both agents 2 and 3 . Agent 2 has negative equity, $e_{2}(P)=-2$. The payment matrix $P$ suffers from two undesirable features. Agent 1 has a positive equity value and outstanding liabilities. Agent 2 has a negative equity value. 


\begin{tabular}{c|ccc|ccc|c|c}
$z$ & & $L$ & & & $P$ & $a(P)$ & $e(P)$ \\
\hline 1 & 0 & 2 & 2 & 0 & 1 & 0 & 3 & 2 \\
1 & 2 & 0 & 2 & 2 & 0 & 2 & 2 & -2 \\
1 & 0 & 0 & 0 & 0 & 0 & 0 & 3 & 3
\end{tabular}

Table 3: An undesirable payment matrix in Example 3.3.

To overcome this situation, we extend the notions of priority of creditors and limited liability defined in the divisible case for proportional division rules by Eisenberg and Noe (2001) to our discrete setup with general bankruptcy rules. ${ }^{2}$

Definition 3.4. Given a financial network $(z, L, b), P \in \mathcal{M}$ is a clearing payment matrix if it satisfies the following three properties.

1. Feasibility: $P \in \mathcal{P}$.

2. Limited liability: For every $i \in I, e_{i}(P) \geq 0$.

3. Priority of creditors: For every $i \in I$, for every $P_{i}^{\prime} \in F_{i}$ such that $P_{i}^{\prime}>P_{i}$ it holds that $a_{i}(P)-\sum_{j \in I} P_{i j}^{\prime}<0$.

A clearing payment matrix is feasible, leads to non-negative equity values, and satisfies priority of creditors. Notice that priority of creditors is satisfied whenever $P_{i}=L_{i}$ since there is no $P_{i}^{\prime} \in F_{i}$ with $P_{i}^{\prime}>P_{i}$ in that case. In the divisible setup, priority of creditors is defined as follows by Eisenberg and Noe (2001): For every $i \in I$, if $P_{i}<L_{i}$, then $e_{i}(P)=0$. In the presence of integer payments, this condition is too strong. We therefore use the requirement in Condition 3 of Definition 3.4 that agent $i$ ends up with negative equity if he chooses a feasible payment that is strictly higher, whereas all other agents remain paying the same. Notice that the definition of $a_{i}(P)$ only depends on how much other agents pay to agent $i$ and not on how much agent $i$ pays to other agents.

The following proposition shows that in case the asset value of an agent is sufficient to pay all his liabilities, then the agent will do so in a clearing payment matrix.

Proposition 3.5. Let $P$ be a clearing payment matrix for the financial network $(z, L, b)$. For every $i \in I$, if $a_{i}(P) \geq \sum_{j \in I} L_{i j}$, then $P_{i}=L_{i}$.

Proof. Suppose not. Let $i \in I$ be such that $a_{i}(P) \geq \sum_{j \in I} L_{i j}$ and $P_{i}<L_{i}$. We define $P_{i}^{\prime}=L_{i}$, which is an element of $F_{i}$ indeed. It holds that

$$
a_{i}(P)-\sum_{j \in I} P_{i j}^{\prime}=a_{i}(P)-\sum_{j \in I} L_{i j} \geq 0,
$$

\footnotetext{
${ }^{2}$ Eisenberg and Noe (2001) refers to 'priority of creditors' as 'priority of debt claims' or 'absolute priority' and to 'limited liability' as 'limited liability (of equity)'.
} 
so $P$ violates priority of creditors and is therefore not a clearing payment matrix, a contradiction.

For the divisible setup with proportional division rules, Eisenberg and Noe (2001) show that when all endowments are positive, then there is a unique clearing payment matrix. Glasserman and Young (2015) present other conditions to get a unique clearing payment matrix. Although in general multiple clearing payment matrices can co-exist, Eisenberg and Noe (2001) show that the final equity is the same irrespective of the clearing matrix that is being used. For the divisible setup with general division rules, uniqueness of final equity values is shown in Groote Schaarsberg et al. (2013).

The next example shows that in the case with indivisibilities, the clearing payment matrix may not be unique even when all initial endowments are positive. More importantly, the resulting values of equity might be different as well.

Example 3.6. As in Example 3.3, we consider a financial network $(z, L, b)$ with three agents $I=\{1,2,3\}$ and endowments and liabilities as presented in Table 2, but replace the priority bankruptcy rules of that example by proportional bankruptcy rules.

Table 4 presents the clearing payment matrix $\underline{P}$ and Table 5 the clearing payment matrix $\bar{P}$. There are no other clearing payment matrices. The matrices $\underline{P}$ and $\bar{P}$ induce different equity values, $e(\underline{P})=(1,1,1)$ and $e(\bar{P})=(0,0,3)$.

\begin{tabular}{c|ccc|ccc|c|c}
$z$ & \multicolumn{3}{|c|}{$L$} & & $\underline{P}$ & $a(\underline{P})$ & $e(\underline{P})$ \\
\hline 1 & 0 & 2 & 2 & 0 & 0 & 0 & 1 & 1 \\
1 & 2 & 0 & 2 & 0 & 0 & 0 & 1 & 1 \\
1 & 0 & 0 & 0 & 0 & 0 & 0 & 1 & 1
\end{tabular}

Table 4: The clearing payment matrix $\underline{P}$ in Example 3.6.

\begin{tabular}{c|ccc|ccc|c|c}
$z$ & \multicolumn{3}{|c|}{$L$} & & $\bar{P}$ & $a(\bar{P})$ & $e(\bar{P})$ \\
\hline 1 & 0 & 2 & 2 & 0 & 1 & 1 & 2 & 0 \\
1 & 2 & 0 & 2 & 1 & 0 & 1 & 2 & 0 \\
1 & 0 & 0 & 0 & 0 & 0 & 0 & 3 & 3
\end{tabular}

Table 5: The clearing payment matrix $\bar{P}$ in Example 3.6.

It holds that $e_{1}(\underline{P})=e_{2}(\underline{P})=1$, so there is some equity left for both agents 1 and 2 when the payment matrix $\underline{P}$ is used. Nevertheless, Condition 3 of Definition 3.4, priority of creditors, holds since there is no higher feasible payment compatible with the asset values of agents 1 and 2 . 


\section{Clearing Payment Matrices as Fixed Points}

In this section, we characterize a clearing payment matrix as a fixed point of an appropriately defined function and derive the bounds for the difference between the values of equity for a given agent in any two clearing payment matrices.

Given a financial network $(z, L, b)$, let $\varphi: \mathcal{P} \rightarrow \mathcal{P}$ be defined by

$$
\varphi_{i j}(P)=b_{i j}\left(a_{i}(P)\right), \quad P \in \mathcal{P}, i, j \in I
$$

Proposition 4.1. Let a financial network $(z, L, b)$ be given. The matrix $P \in \mathcal{P}$ is a clearing payment matrix if and only if $P=\varphi(P)$.

\section{Proof.}

$(\Rightarrow)$

Consider some $i \in I$. We define $P_{i}^{\prime}=\varphi_{i}(P)$. Since $P_{i} \in F_{i}$ and $b_{i}$ is monotonic, it holds that either (a) $P_{i}<P_{i}^{\prime}$, or (b) $P_{i}=P_{i}^{\prime}$, or (c) $P_{i}>P_{i}^{\prime}$.

Case (a). $P_{i}<P_{i}^{\prime}$.

We have that

$$
a_{i}(P)-\sum_{j \in I} P_{i j}^{\prime}=a_{i}(P)-\sum_{j \in I} \varphi_{i j}(P)=a_{i}(P)-\sum_{j \in I} b_{i j}\left(a_{i}(P)\right) \geq 0 .
$$

This contradicts the fact that $P$ satisfies priority of creditors. We conclude that Case (a) cannot occur.

Case (c). $P_{i}>P_{i}^{\prime}$.

Since $P$ satisfies limited liability, it holds that $e_{i}(P) \geq 0$. Let $E_{i} \in \mathbb{N}_{0}$ be such that $P_{i}=b_{i}\left(E_{i}\right)$. From $b_{i}\left(E_{i}\right)=P_{i}>P_{i}^{\prime}=b_{i}\left(a_{i}(P)\right)$, it follows that $a_{i}(P)<E_{i}$. Together with the fact that

$$
\sum_{j \in I} b_{i j}\left(E_{i}\right)=\sum_{j \in I} P_{i j}=a_{i}(P)-e_{i}(P) \leq a_{i}(P)
$$

this implies by Definition 2.4 that $b_{i}\left(a_{i}(P)\right)=b_{i}\left(E_{i}\right)$ and therefore that $P_{i}^{\prime}=P_{i}$, a contradiction to $P_{i}>P_{i}^{\prime}$. We conclude that Case (c) cannot occur.

It now follows that Case (b) holds, so $P_{i}=P_{i}^{\prime}=\varphi_{i}(P)$.

$(\Leftarrow)$

1. Feasibility. It holds that $P \in \mathcal{P}$ by the definition of $\varphi$.

2. Limited liability. For every $i \in I$, we have that

$$
P_{i}=\varphi_{i}(P)=b_{i}\left(a_{i}(P)\right)
$$




$$
e_{i}(P)=a_{i}(P)-\sum_{j \in I} P_{i j}=a_{i}(P)-\sum_{j \in I} b_{i j}\left(a_{i}(P)\right) \geq a_{i}(P)-a_{i}(P)=0 .
$$

3. Priority of creditors. Let $i \in I$ and $P_{i}^{\prime} \in F_{i}$ be such that $P_{i}^{\prime}>P_{i}$. Let $E_{i}^{\prime} \in \mathbb{N}_{0}$ be such that $b_{i}\left(E_{i}^{\prime}\right)=P_{i}^{\prime}$. Since $b_{i}\left(a_{i}(P)\right)=P_{i}<P_{i}^{\prime}=b_{i}\left(E_{i}^{\prime}\right)$, monotonicity of $b_{i}$ implies that $E_{i}^{\prime}>a_{i}(P)$.

Suppose, by contradiction, that $a_{i}(P)-\sum_{j \in I} P_{i j}^{\prime} \geq 0$. Then it holds that

$$
\sum_{j \in I} b_{i j}\left(E_{i}^{\prime}\right)=\sum_{j \in I} P_{i j}^{\prime} \leq a_{i}(P)
$$

Since $E_{i}^{\prime}>a_{i}(P)$, it follows from Definition 2.4 that

$$
P_{i}=b_{i}\left(a_{i}(P)\right)=b_{i}\left(E_{i}^{\prime}\right)
$$

We conclude that $P_{i}=P_{i}^{\prime}$, a contradiction to the assumption that $P_{i}^{\prime}>P_{i}$.

A lattice is a partially ordered set in which every pair of elements has a supremum and an infimum. A complete lattice is a lattice in which every non-empty subset has a supremum and an infimum. Any finite lattice can be shown to be complete. The infimum of a two point set $\left\{x, x^{\prime}\right\}$ is denoted by $x \wedge x^{\prime}$ and its supremum by $x \vee x^{\prime}$.

The matrices in $\mathcal{P}$ are partially ordered by $\leq$, since $\leq$ is a reflexive, transitive, and antisymmetric order on $\mathcal{P}$.

Consider two matrices $P, P^{\prime} \in \mathcal{P}$. We define the matrices $\underline{P}, \bar{P} \in \mathcal{P}$ by

$$
\begin{aligned}
& \underline{P}_{i}=P_{i} \wedge P_{i}^{\prime}, \quad i \in I, \\
& \bar{P}_{i}=P_{i} \vee P_{i}^{\prime}, \quad i \in I .
\end{aligned}
$$

Since $F_{i}$ is totally ordered by $\leq$, it holds that $\underline{P}_{i}$ is either equal to $P_{i}$ or to $P_{i}^{\prime}$. Similarly, it holds that $\bar{P}_{i}$ is either equal to $P_{i}$ or to $P_{i}^{\prime}$. It is now immediate that $\underline{P}, \bar{P} \in \mathcal{P}$ and that $P \wedge P^{\prime}=\underline{P}$ and $P \vee P^{\prime}=\bar{P}$. Every pair of matrices in $\mathcal{P}$ therefore has a supremum and an infimum in $\mathcal{P}$. We conclude that the set $\mathcal{P}$ is a complete lattice.

Proposition 4.2. Consider a financial network $(z, L, b)$. The set of clearing payment matrices is a complete lattice. In particular, there exists a least clearing payment matrix $P^{-}$ and a greatest clearing payment matrix $P^{+}$.

Proof. We show that $\varphi$ is monotone. Let $P, P^{\prime} \in \mathcal{P}$ be such that $P \leq P^{\prime}$. For every $i \in I$, it holds that

$$
\varphi_{i}(P)=b_{i}\left(a_{i}(P)\right)=b_{i}\left(z_{i}+\sum_{j \in I} P_{j i}\right) \leq b_{i}\left(z_{i}+\sum_{j \in I} P_{j i}^{\prime}\right)=b_{i}\left(a_{i}\left(P^{\prime}\right)\right)=\varphi_{i}\left(P^{\prime}\right)
$$


where the inequality follows from the monotonicity of $b_{i}$.

By Tarski's fixed point theorem (Tarski, 1955), the set of fixed points of $\varphi$ is a complete lattice with respect to $\leq$. It follows that the set of fixed points has a least and a greatest element. By Proposition 4.1, the set of fixed points of $\varphi$ is equal to the set of clearing payment matrices.

Example 3.6 shows that two clearing payment matrices may lead to different values of equity. To analyze the size of the possible differences, we introduce the following notation. For every $i \in I$, for every $P_{i} \in F_{i} \backslash\left\{L_{i}\right\}$, we define $S_{i}\left(P_{i}\right)$ as the unique successor of $P_{i}$, i.e. the lowest feasible payment vector that is strictly greater than $P_{i}$. Note that $S_{i}\left(P_{i}\right)$ is not defined if $P_{i}=L_{i}$.

For every $i \in I$, the number $\kappa_{i}$ equals the maximal difference between total payments in two consecutive feasible payment vectors for agent $i$. If $F_{i}$ consists of a single element, so $F_{i}=\left\{L_{i}\right\}=\left\{0^{I}\right\}$, then we define $\kappa_{i}=1$. Otherwise, $F_{i}$ has at least two elements and we define

$$
\kappa_{i}=\max _{P_{i} \in F_{i} \backslash\left\{L_{i}\right\}} \sum_{j \in I}\left(S_{i j}\left(P_{i}\right)-P_{i j}\right) .
$$

The bankruptcy rules discussed in Example 2.8 give three typical numbers for $\kappa_{i}$. If $b_{i}$ is a priority bankruptcy rule, then $\kappa_{i}=1$. If $b_{i}$ corresponds to the all or nothing bankruptcy rule and $L_{i}>0$, then $\kappa_{i}=\sum_{j \in I} L_{i j}$ equals the sum of the liabilities of agent $i$. It is easy to see that if $b_{i}$ is the proportional bankruptcy rule and $L_{i}>0$, then $\kappa_{i}$ is at most as large as the number of non-zero liabilities of agent $i$, which in turn is less than the number of agents. The latter inequality holds for any induced bankruptcy rule.

Proposition 4.3. Consider a financial network $(z, L, b)$ such that for some $i \in I$ it holds that $L_{i}>0$ and the bankruptcy rule $b_{i}$ is induced by the division rule $d_{i}$. Let $\lambda_{i}=\#\{j \in$ $\left.I \mid L_{i j}>0\right\}$ be the number of non-zero liabilities of agent $i$. It holds that $\kappa_{i} \leq \lambda_{i} \leq n-1$.

Proof. Take any $P_{i} \in F_{i} \backslash\left\{L_{i}\right\}$. Suppose there is $j \in I$ such that $S_{i j}\left(P_{i}\right)-P_{i j} \geq 2$. Let $E, E^{\prime \prime} \in \mathbb{R}_{+}$be such that $P_{i j}=\left\lfloor d_{i j}(E)\right\rfloor$ and $S_{i j}\left(P_{i}\right)=\left\lfloor d_{i j}\left(E^{\prime \prime}\right)\right\rfloor$. By continuity and monotonicity of $d_{i}$, there is $E^{\prime} \in \mathbb{R}_{+}$such that $E<E^{\prime}<E^{\prime \prime}$ and

$$
P_{i j}=\left\lfloor d_{i j}(E)\right\rfloor<\left\lfloor d_{i j}\left(E^{\prime}\right)\right\rfloor<\left\lfloor d_{i j}\left(E^{\prime \prime}\right)\right\rfloor=S_{i j}\left(P_{i}\right) .
$$

By monotonicity of $d_{i}$, we have that $P_{i}<\left\lfloor d_{i}\left(E^{\prime}\right)\right\rfloor<S_{i}\left(P_{i}\right)$. Since $\left\lfloor d_{i}\left(E^{\prime}\right)\right\rfloor \in F_{i}$, this contradicts the definition of $S_{i}\left(P_{i}\right)$.

Consequently, it holds for every $j \in I$ that $S_{i j}\left(P_{i}\right)-P_{i j} \in\{0,1\}$, so

$$
\sum_{j \in I}\left(S_{i j}\left(P_{i}\right)-P_{i j}\right)=\sum_{\left\{j \in I \mid L_{i j}>0\right\}}\left(S_{i j}\left(P_{i}\right)-P_{i j}\right) \leq \#\left\{j \in I \mid L_{i j}>0\right\}=\lambda_{i} \leq n-1,
$$


and therefore

$$
\kappa_{i}=\max _{P_{i} \in F_{i} \backslash\left\{L_{i}\right\}} \sum_{j \in I}\left(S_{i j}\left(P_{i}\right)-P_{i j}\right) \leq \lambda_{i} \leq n-1
$$

The numbers $\kappa_{i}$ for $i \in I$ can be used to provide lower and upper bounds on the maximum difference in equity that results from two different clearing payment matrices.

Proposition 4.4. Consider a financial network $(z, L, b)$ and two clearing payment matrices $P$ and $P^{\prime}$ with $P \leq P^{\prime}$. For every $i \in I$, the difference between the value of equity at $P$ and $P^{\prime}$ satisfies $-\left(\kappa_{i}-1\right) \leq e_{i}\left(P^{\prime}\right)-e_{i}(P) \leq \sum_{j \in I \backslash\{i\}}\left(\kappa_{j}-1\right)$.

Proof. We argue first that, for every $i \in I$,

$$
\max \left\{0, a_{i}(P)-\sum_{j \in I} L_{i j}\right\}=a_{i}(P)-\sum_{j \in I} P_{i j}-\varepsilon_{i}(P)=e_{i}(P)-\varepsilon_{i}(P),
$$

where

$$
\varepsilon_{i}(P) \in \begin{cases}\{0\}, & \text { if } a_{i}(P) \geq \sum_{j \in I} L_{i j}, \\ \left\{0, \ldots, \kappa_{i}-1\right\}, & \text { if } a_{i}(P)<\sum_{j \in I} L_{i j} .\end{cases}
$$

We distinguish two cases: (a) $a_{i}(P) \geq \sum_{j \in I} L_{i j}$ and (b) $a_{i}(P)<\sum_{j \in I} L_{i j}$.

Case (a). $a_{i}(P) \geq \sum_{j \in I} L_{i j}$.

It holds that

$$
\max \left\{0, a_{i}(P)-\sum_{j \in I} L_{i j}\right\}=a_{i}(P)-\sum_{j \in I} L_{i j}=a_{i}(P)-\sum_{j \in I} P_{i j}=e_{i}(P)
$$

where the second equality follows from Proposition 3.5. It follows that $\varepsilon_{i}(P)=0$.

Case (b). $a_{i}(P)<\sum_{j \in I} L_{i j}$.

It holds that

$$
\varepsilon_{i}(P)=e_{i}(P)-\max \left\{0, a_{i}(P)-\sum_{j \in I} L_{i j}\right\}=e_{i}(P)
$$

Since $P$ is a clearing payment matrix, it follows that $\varepsilon_{i}(P) \in \mathbb{N}_{0}$. Moreover, we have by Proposition 4.1 that

$$
\sum_{j \in I} P_{i j}=\sum_{j \in I} b_{i j}\left(a_{i}(P)\right) \leq \min \left\{\sum_{j \in I} L_{i j}, a_{i}(P)\right\}=a_{i}(P)<\sum_{j \in N} L_{i j} .
$$


Since $P$ satisfies priority of creditors, we have that

$$
a_{i}(P)-\sum_{j \in I} S_{i j}\left(P_{i}\right)<0 .
$$

Finally, using Equation (4), it follows that

$$
\varepsilon_{i}(P)=e_{i}(P)=a_{i}(P)-\sum_{j \in I} P_{i j} \leq a_{i}(P)-\sum_{j \in I} S_{i j}\left(P_{i}\right)+\kappa_{i} \leq \kappa_{i}-1 .
$$

This completes the proof that Equation (3) holds.

Let some $i \in I$ be given. Since $P \leq P^{\prime}$, we have that

$$
\max \left\{0, a_{i}(P)-\sum_{j \in I} L_{i j}\right\} \leq \max \left\{0, a_{i}\left(P^{\prime}\right)-\sum_{j \in I} L_{i j}\right\},
$$

so it follows from Equation (3) that

$$
e_{i}(P)-\varepsilon_{i}(P) \leq e_{i}\left(P^{\prime}\right)-\varepsilon_{i}\left(P^{\prime}\right) .
$$

Rewriting this inequality, we obtain

$$
e_{i}\left(P^{\prime}\right)-e_{i}(P) \geq \varepsilon_{i}\left(P^{\prime}\right)-\varepsilon_{i}(P) \geq-\left(\kappa_{i}-1\right) .
$$

Using Equation (2), we find that

$$
e_{i}\left(P^{\prime}\right)-e_{i}(P)=\sum_{j \in I \backslash\{i\}}\left(e_{j}(P)-e_{j}\left(P^{\prime}\right)\right) \leq \sum_{j \in I \backslash\{i\}}\left(\kappa_{j}-1\right),
$$

which completes the proof.

By Proposition 4.2, it holds for any clearing payment matrix $P$ that $P^{-} \leq P \leq P^{+}$. Natural choices in Proposition 5.1 are therefore $P=P^{-}$and $P^{\prime}=P^{+}$.

In Example 3.6 it holds that $\kappa_{1}=\kappa_{2}=2$ and $\kappa_{3}=1$. There are only two possible clearing payment matrices, $\underline{P}$ and $\bar{P}$. It holds that $e_{1}(\bar{P})-e_{1}(\underline{P})=e_{2}(\bar{P})-e_{2}(\underline{P})=$ $-1=-\left(\kappa_{1}-1\right)=-\left(\kappa_{2}-1\right)$, so the lower bound of Proposition 4.4 is tight. Since $e_{3}(\bar{P})-e_{3}(\underline{P})=2=\left(\kappa_{1}-1\right)+\left(\kappa_{2}-1\right)$, the upper bound of Proposition 4.4 is tight as well.

In a financial network with priority bankruptcy rules, or more generally, in a financial network where $\kappa_{i}=1$ for every $i \in I$, Proposition 4.4 implies that the difference between the value of equity for a given agent at the least clearing payment matrix $P^{-}$and any clearing payment matrix $P$ is zero. The value of equity is uniquely determined in this case.

In a financial network with proportional bankruptcy rules, or more generally, in a financial network where all bankruptcy rules are induced by division rules, the difference 
between the value of equity of agent $i$ at the greatest clearing payment matrix $P^{+}$and any clearing payment matrix $P$ is bounded between $-\lambda_{i} \geq-(n-1)$ and $\sum_{j \in I \backslash\{i\}}\left(\lambda_{j}-\right.$ $1) \leq(n-1)(n-1-1)=(n-1)(n-2)$ by Proposition 5.1. If all bankruptcy rules are all or nothing, then this difference is bounded between $-\left(\kappa_{i}-1\right) \geq-\sum_{j \in I} L_{i j}$ and $\sum_{j \in I \backslash\{i\}}\left(\kappa_{j}-1\right) \leq \sum_{j \in I \backslash\{i\}} \sum_{k \in I} L_{j k}$.

\section{$5 \quad$ Decentralized Clearing}

The literature on default in financial networks has so far always considered centralized clearing procedures. In this section, we show how any decentralized clearing process in a large class converges to the least clearing payment matrix. Bounds on equity differences with the greatest clearing payment matrix are given by Proposition 4.4.

In a centralized clearing procedure, implicitly all agents are filing for bankruptcy simultaneously and a clearing payment matrix is centrally computed. One possibility to do so is by formulating an integer programming problem where the objective is to maximize the total payments that are made subject to feasibility constraints, see also Eisenberg and Noe (2001) for a similar formulation in the divisible case with proportional division rules.

$$
\begin{aligned}
& \max _{P \in \mathcal{P}} \sum_{i \in I} \sum_{j \in J} P_{i j}, \\
& \text { subject to } \sum_{j \in I}\left(P_{i j}-P_{j i}\right) \leq z_{i}, \quad i \in I .
\end{aligned}
$$

Proposition 5.1. Consider a financial network $(z, L, b)$. The payment matrix $P^{+}$is the unique solution to the maximization problem in (5).

Proof. Assume the payment matrix $P^{\prime}$ is a solution to the maximization problem in (5). We show next that $P^{\prime}$ satisfies the conditions of Definition 3.4, so $P^{\prime}$ is a clearing payment matrix.

1. Feasibility. Since $P^{\prime} \in \mathcal{P}$, feasibility is satisfied, that is payments are made in accordance with bankruptcy rules.

2. Limited liability. For every $i \in I$, since $\sum_{j \in I}\left(P_{i j}^{\prime}-P_{j i}^{\prime}\right) \leq z_{i}$, we have

$$
e_{i}\left(P^{\prime}\right)=z_{i}+\sum_{j \in I}\left(P_{j i}^{\prime}-P_{i j}^{\prime}\right) \geq 0
$$

so $P^{\prime}$ satisfies limited liability.

3. Priority of creditors. Suppose there is $i^{\prime} \in I$ and $P_{i^{\prime}}^{*} \in F_{i^{\prime}}$ such that $P_{i^{\prime}}^{*}>P_{i^{\prime}}^{\prime}$ and

$$
a_{i^{\prime}}\left(P^{\prime}\right)-\sum_{j \in I} P_{i^{\prime} j}^{*} \geq 0 .
$$


Complete the definition of the matrix $P^{*}$ by setting $P_{i}^{*}=P_{i}^{\prime}$ for $i \in I \backslash\left\{i^{\prime}\right\}$. We have that

$$
\sum_{j \in I}\left(P_{i^{\prime} j}^{*}-P_{j i^{\prime}}^{*}\right)=\sum_{j \in I}\left(P_{i^{\prime} j}^{*}-P_{j i^{\prime}}^{\prime}\right) \leq a_{i^{\prime}}\left(P^{\prime}\right)-\sum_{j \in I} P_{j i^{\prime}}^{\prime}=z_{i^{\prime}}+\sum_{j \in I}\left(P_{j i^{\prime}}^{\prime}-P_{j i^{\prime}}^{\prime}\right)=z_{i^{\prime}}
$$

where the inequality follows from (6). For every $i \in I \backslash\left\{i^{\prime}\right\}$, it holds that

$$
\sum_{j \in I}\left(P_{i j}^{*}-P_{j i}^{*}\right)=\sum_{j \in I}\left(P_{i j}^{\prime}-P_{j i}^{*}\right) \leq \sum_{j \in I}\left(P_{i j}^{\prime}-P_{j i}^{\prime}\right) \leq z_{i}
$$

where the last inequality follows since $P^{\prime}$ is a solution to the maximization problem in (5).

We have shown that $P^{*}$ satisfies all feasibility constraints of the maximization problem in (5). Since $P^{*}>P^{\prime}$, we obtain a contradiction to $P^{\prime}$ being an optimal solution.

Consequently, for every $i \in I$, for every $P_{i}^{*} \in F_{i}$ such that $P_{i}^{*}>P_{i}^{\prime}$, it holds that $a_{i}\left(P^{\prime}\right)-\sum_{j \in I} P_{i j}^{*}<0$ and $P^{\prime}$ satisfies priority of creditors.

A solution to the maximization problem in (5) is therefore a clearing payment matrix. We show next that the greatest clearing payment matrix $P^{+}$, guaranteed to exist by Proposition 4.2, satisfies the feasibility constraints of the maximization problem (5).

It holds that $P^{+} \in \mathcal{P}$. Since $P^{+}$satisfies limited liability, for every $i \in I$ it holds that

$$
e_{i}\left(P^{+}\right)=z_{i}+\sum_{j \in I}\left(P_{j i}^{+}-P_{i j}^{+}\right) \geq 0
$$

The proposition now follows from the observation that $P^{+}$is the greatest clearing payment matrix and that the objective function in (5) is strictly monotonic in all entries of $P$.

The only feature of the objective function in maximization problem (5) that is used in the proof of Proposition 5.1 is its strict monotonicity in each entry of $P$. If we replace the objective function $\sum_{i \in I} \sum_{j \in I} P_{i j}$ in (5) by any objective function $o: \mathcal{P} \rightarrow \mathbb{R}$ that is strictly monotonic on $\mathcal{P}$, we get $P^{+}$as the unique solution. So even if the objective function is such that some agents are favored to others, i.e. carry a higher weight in the objective function, or if smaller payments are relatively more important than bigger payments, i.e. the marginal benefits from additional payment are decreasing and the objective function is concave, it would still be the case that $P^{+}$emerges as the unique solution.

Eisenberg and Noe (2001) formulate the fictitious default algorithm to find a clearing payment matrix for the divisible case with proportional division rules. It starts by assuming that all agents pay their liabilities in full and then checks whether defaults occur. If no firstorder default arises, then the algorithm is terminated. Otherwise, it is assumed that the agents involved in first-order defaults end up with zero equity, whereas the other agents pay their liabilities in full, a problem that corresponds to solving a system of linear equations. If no second-order defaults occur, then the algorithm is terminated. Otherwise it proceeds 
by setting the equity of first-order and second-order defaulting agents to zero, and so on. It is shown that this algorithm terminates in at most $n$ steps to the greatest clearing payment matrix. Variations on this algorithm have been presented in Rogers and Veraart (2013) and Elliott et al. (2014).

The centralized approaches towards clearing have their limitations. In reality, agents do not file for bankruptcy simultaneously and even for agents that are declared bankrupt, the settlement of payments does not occur at the same time. Indeed, not all assets of a bankrupt agent are equally liquid and the liquidation process may take considerable time. Moreover, examples like the Lehman bankruptcy or the European sovereign debt problems involve many different (international) institutions. As emphasized by Elsinger et al. (2006) and Gai and Kapadia (2010), the complexity of the financial system means that policymakers have only partial information about the true linkages between financial intermediaries. The information that is required for a centralized approach is simply not available.

In this section, we present a general class of decentralized clearing processes with the following features. At each point in time, an agent is selected by means of a process that is potentially history-dependent and stochastic. This agent would typically be an agent that has filed for bankruptcy. Next, the selected agent makes any amount of feasible payments to the other agents. The amount that is paid depends only on local information and is determined by a process that again is potentially history-dependent and stochastic. The only requirement that we make is that the selected agent be eligible, that is can make a positive incremental payment without ending up with negative equity.

Definition 5.2. Let $(z, L, b)$ be a financial network. The set of eligible agents at $P \in \mathcal{P}$ is equal to

$$
G(P)=\left\{i \in I \mid \exists P_{i}^{\prime} \in F_{i} \text { such that } P_{i}^{\prime}>P_{i} \text { and } a_{i}(P)-\sum_{j \in I} P_{i j}^{\prime} \geq 0\right\} .
$$

It is easily verified that a payment matrix $P \in \mathcal{P}$ violates priority of creditors if and only if $G(P) \neq \emptyset$.

The requirement of making a payment that does not violate limited liability addresses another problematic aspect of the centralized approach, which is that the payment matrices as derived in for instance the intermediate steps of the fictitious default algorithm lead to negative equity values and are therefore not implementable.

Next, we define the general class of decentralized clearing processes described before.

Definition 5.3. Let some financial network $(z, L, b)$ be given. A decentralized clearing process operates as follows. 
Step 1 We define $k=1$ and $P^{1}=0^{I \times I}$. If $G\left(P^{1}\right)=\emptyset$, then stop. Otherwise, continue to Step 2.

Step 2 Select any agent $i_{k+1} \in G\left(P^{k}\right)$ and any payment vector $P_{i_{k+1}}^{k+1} \in F_{i_{k+1}}$ such that $P_{i_{k+1}}^{k+1}>P_{i_{k+1}}^{k}$ and $a_{i_{k+1}}\left(P^{k}\right)-\sum_{j \in I} P_{i_{k+1} j}^{k+1} \geq 0$. The matrix $P^{k+1}$ is completed by defining $P_{j}^{k+1}=P_{j}^{k}$ for $j \in I \backslash\left\{i_{k+1}\right\}$.

Step 3 If $G\left(P^{k+1}\right)=\emptyset$, then stop. Otherwise, increase the value of $k$ by 1 and return to Step 2.

We start from $P^{1}=0^{I \times I}$. This payment matrix satisfies feasibility and limited liability, and violates priority of creditors if and only if $G\left(P^{1}\right) \neq \emptyset$. In Step 2 of the process, the selected eligible agent $i_{k+1} \in G\left(P^{k}\right)$ is required to make a positive (not necessarily maximal) additional payment $P_{i_{k+1}}^{k+1}-P_{i_{k+1}}^{k}$. We think of the rows of the payment matrices as generated by the decentralized clearing process as the total payments that have been made so far. The payment matrix $P^{k+1}$ clearly satisfies feasibility. It satisfies limited liability by construction for the selected agent. Since the payments for the other agents only increase, it can be shown by induction that for them limited liability is satisfied as well. The payment matrix $P^{k+1}$ violates priority of creditors if and only if $G\left(P^{k+1}\right) \neq \emptyset$.

There are many alternative ways in which agents can be selected in Step 2 of the decentralized clearing process. Typically, the selection would be determined by the timing of agents filing for bankruptcy and the timing of the liquidation of their assets. The payment vector in Step 2 can be the greatest payment vector that satisfies limited liability, but it is also possible that the assets of a defaulting agent are not all simultaneously liquidated and therefore sequential payments to the agent's creditors are made. In this way, a decentralized clearing process allows for selling the liquid assets first and the illiquid ones later.

We illustrate the decentralized clearing process by means of the following example.

Example 5.4. As in Examples 3.3 and 3.6, we consider the financial network $(z, L, b)$ with three agents $I=\{1,2,3\}$ and endowments and liabilities as presented in Table 6 .

\begin{tabular}{l|lll}
$z$ & & \multicolumn{3}{|c}{$L$} & \\
\hline 1 & 0 & 2 & 2 \\
1 & 2 & 0 & 2 \\
1 & 0 & 0 & 0
\end{tabular}

Table 6: The endowments and liabilities of the agents in Example 5.4.

We first consider the case where $b$ only involves proportional bankruptcy rules. The 
sets of feasible payments are given by

$$
\begin{aligned}
& F_{1}=\{(0,0,0),(0,1,1),(0,2,2)\} \\
& F_{2}=\{(0,0,0),(1,0,1),(2,0,2)\} \\
& F_{3}=\{(0,0,0)\} .
\end{aligned}
$$

We start from $P^{1}=0^{I \times I}$. Under $P^{1}$ it holds that $G\left(P^{1}\right)=\emptyset$, so no agent is eligible to be selected. Indeed, agents 1 and 2 both have an asset value of 1 unit, but since $\sum_{j \in I}\left(S_{1 j}\left(P_{1}^{1}\right)-P_{1 j}^{1}\right)=\sum_{j \in I}\left(S_{2 j}\left(P_{2}^{1}\right)-P_{2 j}^{1}\right)=2$, their next higher payment vector requires an asset value of 2 units. We stop at the least clearing payment matrix $P^{-}$as derived in Example 3.6.

Now let $b$ only involve priority bankruptcy rules, where agent 1 has priority over agent 2 and agent 2 has priority over agent 3 . The sets of feasible payments are given by

$$
\begin{aligned}
& F_{1}=\{(0,0,0),(0,1,0),(0,2,0),(0,2,1),(0,2,2)\} \\
& F_{2}=\{(0,0,0),(1,0,0),(2,0,0),(2,0,1),(2,0,2)\} \\
& F_{3}=\{(0,0,0)\}
\end{aligned}
$$

\begin{tabular}{|c|c|c|c|c|c|c|c|c|c|c|c|c|c|c|}
\hline \multicolumn{3}{|c|}{$P^{1}$} & \multicolumn{3}{|c|}{$P^{2}$} & \multicolumn{3}{|c|}{$P^{3}$} & \multicolumn{3}{|c|}{$P^{4}$} & \multicolumn{3}{|c|}{$P^{5}$} \\
\hline 0 & 0 & 0 & 0 & 1 & 0 & 0 & 1 & 0 & 0 & 2 & 1 & 0 & 2 & 1 \\
\hline 0 & 0 & 0 & 0 & 0 & 0 & 2 & 0 & 0 & 2 & 0 & 0 & 2 & 0 & 1 \\
\hline 0 & 0 & 0 & 0 & 0 & 0 & 0 & 0 & 0 & 0 & 0 & 0 & 0 & 0 & 0 \\
\hline
\end{tabular}

Let us start the process again with $P^{1}=0^{I \times I}$. Under $P^{1}$, both agents 1 and 2 are eligible to be selected, $G\left(P^{1}\right)=\{1,2\}$. Suppose agent 1 files for bankruptcy first. Since $a_{1}\left(P^{1}\right)=1$, the only possible payment vector is $(0,1,0)$, where agent 1 pays 1 unit to agent 2 and the payment matrix is updated to $P^{2}$ as presented in Table 7.

Table 7: The total payments in iterations 1, 2, 3, 4, and 5 in Example 5.4.

Under $P^{2}$ only agent 2 is eligible, $G\left(P^{2}\right)=\{2\}$. Since $a_{2}\left(P^{2}\right)=2$, there are now two possible payment vectors for agent $2,(1,0,0)$ and $(2,0,0)$. Suppose the liquidator always selects the maximal payment compatible with limited liability, $b_{2}\left(a_{2}\left(P^{2}\right)\right)=(2,0,0)$. Agent 2 pays 2 units to agent 1 and 0 units to agent 3 . The payment matrix is now $P^{3}$ as presented in Table 7.

Under $P^{3}$ only agent 1 is eligible, $G\left(P^{3}\right)=\{1\}$. Since $a_{1}\left(P^{3}\right)=3$, there are two possible payment vectors for agent $1,(0,2,0)$ and $(0,2,1)$. Under the maximal payment of $b_{1}\left(a_{1}\left(P^{3}\right)\right)=(0,2,1)$, agent 1 makes an additional transfer of 1 unit to agent 2 and makes a transfer of 1 unit to agent 3 , and the new payment matrix is equal to $P^{4}$. At $P^{4}$, it holds that $G\left(P^{4}\right)=\{2\}$, the only possible payment vector is $(2,0,1)$, so agent 2 makes a transfer of 1 unit to agent 3 . Since $G\left(P^{5}\right)=\emptyset$, there are no more eligible agents and the process is 
over at the payment matrix $P^{5}$ of Table 7 . In this example, the matrix $P^{5}$ is the unique clearing payment matrix.

Proposition 5.5. Given a financial network $(z, L, b)$, a decentralized clearing process terminates in a finite number of iterations with the least clearing payment matrix $\mathrm{P}^{-}$.

Proof. Finite convergence is satisfied, since total payments made increase by at least one unit in each iteration and total payments have to be bounded above by the amounts involved in the liabilities, a finite number.

Assume that $\left(P^{1}, \ldots, P^{K}\right)$ corresponds to the realization of a decentralized process. We show that $P^{K}$ is a clearing payment matrix by verifying the conditions of Definition 3.4.

1. Feasibility. In each iteration a feasible payment vector is selected, thus $P^{K} \in \mathcal{P}$.

2. Limited liability. It is immediate to verify that $P^{1}=0^{I \times I}$ satisfies limited liability. We proceed by induction. Assume, for some $k<K, P^{k}$ satisfies limited liability. For the selected agent $i_{k+1}$ it holds that

$$
\sum_{j \in I} P_{i_{k+1} j}^{k+1} \leq a_{i_{k+1}}\left(P^{k}\right)=a_{i_{k+1}}\left(P^{k+1}\right) .
$$

For every agent $i \in I \backslash\left\{i_{k+1}\right\}$, we have

$$
\sum_{j \in I} P_{i j}^{k+1}=\sum_{j \in I} P_{i j}^{k} \leq a_{i}\left(P^{k}\right) \leq a_{i}\left(P^{k+1}\right),
$$

where the first inequality follows from the induction hypothesis.

We conclude that $P^{k}$ satisfies limited liability for every $k \in\{1, \ldots, K\}$.

3. Priority of creditors. Suppose $P^{K}$ does not satisfy priority of creditors. It follows that $G\left(P^{K}\right) \neq \emptyset$, which contradicts that the decentralized clearing process terminates at $P^{K}$.

We have shown that $P^{K}$ is clearing payment matrix. To show that it is the least clearing payment matrix, let $k$ be the last iteration in $\{1, \ldots, K\}$ such that $P^{k} \leq P^{-}$. Notice that such a $k$ exists since $P^{1} \leq P^{-}$.

Suppose $k<K$. We argue first that $P^{k+1} \leq \varphi\left(P^{k}\right)$. By construction of $P_{i_{k+1}}^{k+1}$ it holds that $\sum_{j \in I} P_{i_{k+1} j}^{k+1} \leq a_{i_{k+1}}\left(P^{k}\right)$, so clearly $P_{i_{k+1}}^{k+1} \leq b_{i_{k+1}}\left(a_{i_{k+1}}\left(P^{k}\right)\right)=\varphi_{i_{k+1}}\left(P^{k}\right)$. For $i \in I \backslash\left\{i_{k+1}\right\}$, it holds that

$$
P_{i}^{k+1}=P_{i}^{k} \leq b_{i}\left(a_{i}\left(P^{k}\right)\right)=\varphi_{i}\left(P^{k}\right)
$$

where the inequality follows from the fact that $P^{k}$ satisfies limited liability.

Then we have that

$$
P^{k+1} \leq \varphi\left(P^{k}\right) \leq \varphi\left(P^{-}\right)=P^{-},
$$


where the second inequality follows from the monotonicity of $\varphi$ as shown in the proof of Proposition 4.2 and the equality from the fact that $P^{-}$is a fixed point of $\varphi$ by Proposition 4.1. This contradicts the definition of $k$ as the last iteration such that $P^{k} \leq P^{-}$.

Consequently, we have that $k=K$. Since $P^{K} \leq P^{-}$and $P^{K}$ is a clearing payment matrix, it follows that $P^{K}=P^{-}$.

Whereas the centralized procedures yield the greatest payment matrix $P^{+}$, a decentralized process converges to the least payment matrix $P^{-}$. Surprisingly, the convergence to $P^{-}$is independent of the precise specification of the decentralized process in the following sense. The process to select eligible agents is potentially history-dependent and stochastic. The additional payments are only required to be positive and not necessarily maximal, taking into account limited liability. They may be determined in a potentially historydependent and stochastic way too. What is important is that selected agents pay some extra amount in accordance with the bankruptcy rules. If payments are not in accordance with the bankruptcy rules, then one might end up with a different clearing payment matrix. For instance, in case agents could decide themselves whom to pay, they have incentives to pay those agents on which they have claims. Obviously, without enforcement of payments, agents would prefer not to pay at all.

Whether the difference between a centralized procedure and a decentralized process is substantial or not depends on the values of $\kappa_{i}$, see Proposition 4.4.

\section{The Divisible Case}

In this section we analyze the divisible setup and relate it to our discrete setup.

A financial network $(z, L, d)$ in the divisible case consists of endowments $z \in \mathbb{R}_{+}^{I}$, a liability matrix $L \in \mathbb{R}_{+}^{I \times I}$, and division rules $d=\left(d_{i}\right)_{i \in I}$ with $d_{i}: \mathbb{R}_{+} \rightarrow \mathbb{R}_{+}^{I}$. As before, we use $\mathcal{P}$ for the set of feasible payment matrices, so

$$
\mathcal{P}=\left\{P \in \mathbb{R}_{+}^{I \times I} \mid \forall i \in I, P_{i} \in d_{i}\left(\mathbb{R}_{+}\right)\right\}
$$

A clearing payment matrix is now defined as follows.

Definition 6.1. Given a financial network $(z, L, d)$ in the divisible case, $P \in \mathbb{R}_{+}^{I \times I}$ is a clearing payment matrix if it satisfies the following three properties.

1. Feasibility: $P \in \mathcal{P}$.

2. Limited liability: For every $i \in I, e_{i}(P) \geq 0$.

3. Priority of creditors: For every $i \in I$, if $P_{i}<L_{i}$, then $e_{i}(P)=0$. 
It follows from the results in Groote Schaarsberg et al. (2013) that a clearing payment matrix exists in the divisible case and that each clearing payment matrix leads to the same value of equity, thereby generalizing the same result for the case with proportional division rules by Eisenberg and Noe (2001). We denote this value of equity by $e^{*} \in \mathbb{R}_{+}^{I}$.

The assumption of perfectly divisible payments is clearly an abstraction. We are interested in the question whether it serves as a good approximation for the case with a smallest unit of account, when this smallest unit converges to zero.

For $m \in \mathbb{N}$, let $1 / m$ be the unit of account. To each financial network $(z, L, d)$ in the divisible case, we associate a financial network $\left(z(m), L(m), b^{d}(m)\right)$, where $z(m)=\lfloor m \cdot z\rfloor$, $L(m)=\lfloor m \cdot L\rfloor$, and $b^{d}(m)=b^{\left\lfloor m \cdot d\left(\mathbb{R}_{+}\right)\right\rfloor}$. Amounts now correspond to multiples of $1 / m$, so we have to divide $z(m), L(m)$, and $b^{d}(m)$ by $m$ to compare them to $z, L$, and $d$, respectively.

Asset and equity values resulting from a payment matrix $P \in \mathcal{M}$ in the model with unit of account $1 / m$ are denoted by $a^{m}(P)$ and $e^{m}(P)$, respectively. We have

$$
\begin{aligned}
& a_{i}^{m}(P)=z_{i}(m)+\sum_{j \in I} P_{j i}, \quad i \in I, \\
& e_{i}^{m}(P)=a_{i}^{m}(P)-\sum_{j \in I} P_{i j}, \quad i \in I .
\end{aligned}
$$

The following proposition gives an affirmative answer to our question.

Proposition 6.2. Let $(z, L, d)$ be a financial network in the divisible case. For every $m \in \mathbb{N}$, let $P^{m}$ be a clearing payment matrix of the financial network $\left(z(m), L(m), b^{d}(m)\right)$. Then $\lim _{m \rightarrow \infty}(1 / m) \cdot e^{m}\left(P^{m}\right)=e^{*}$.

Proof. Since $\left((1 / m) \cdot P^{m}\right)_{m \in \mathbb{N}}$ is a bounded sequence, we can assume without loss of generality that it converges to a matrix $\bar{P}$.

We show that $\bar{P}$ is a clearing payment matrix for the financial network $(z, L, d)$ in the divisible case by verifying the three conditions of Definition 6.1.

1. Feasibility. Take some $i \in I$. It holds that $P_{i}^{m} \in\left\lfloor m \cdot d_{i}\left(\mathbb{R}_{+}\right)\right\rfloor$, so $(1 / m) \cdot P_{i}^{m}=$ $(1 / m) \cdot\left\lfloor m \cdot d_{i}\left(E_{i}^{m}\right)\right\rfloor$ for some $E_{i}^{m} \in \mathbb{R}_{+}$. It follows that $(1 / m) \cdot\left\lfloor m \cdot d_{i}\left(E_{i}^{m}\right)\right\rfloor=\left\lfloor d_{i}\left(E_{i}^{m}\right)\right\rfloor_{m}$, where $\lfloor x\rfloor_{m}$ denotes the greatest multiple of $1 / m$ that is less than or equal to $x \in \mathbb{R}_{+}$. The Hausdorff distance of the point $\left\lfloor d_{i}\left(E_{i}^{m}\right)\right\rfloor_{m}$ to the compact set $d_{i}\left(\mathbb{R}_{+}\right)$is less than or equal to $1 / m$ under $\|\cdot\|_{\infty}$. It then follows that

$$
\bar{P}_{i}=\lim _{m \rightarrow \infty} \frac{1}{m} \cdot P_{i}^{m}=\lim _{m \rightarrow \infty}\left\lfloor d_{i}\left(E_{i}^{m}\right)\right\rfloor_{m} \in d_{i}\left(\mathbb{R}_{+}\right) .
$$

2. Limited liability. Take some $i \in I$. By limited liability in Definition $3.4, e_{i}^{m}\left(P^{m}\right) \geq 0$, so $(1 / m) \cdot e_{i}^{m}\left(P^{m}\right) \geq 0$, and

$$
e_{i}\left(\bar{P}_{i}\right)=\lim _{m \rightarrow \infty}(1 / m) \cdot e_{i}^{m}\left(P^{m}\right) \geq 0 .
$$


3. Priority of creditors. Assume $i \in I$ is such that $\bar{P}_{i}<L_{i}$. For $m$ sufficiently large, it holds that $P_{i}^{m}<\left\lfloor m \cdot L_{i}\right\rfloor$. By priority of creditors in Definition 3.4 it follows that

$$
a_{i}^{m}\left(P^{m}\right)<\sum_{j \in I} S_{i j}^{m}\left(P_{i}^{m}\right) \leq \sum_{j \in I} P_{i j}^{m}+n-1,
$$

where $S_{i}^{m}\left(P_{i}^{m}\right)$ denotes the unique successor of $P_{i}^{m}$. We find that

$$
e_{i}^{m}\left(P^{m}\right)=a_{i}^{m}\left(P^{m}\right)-\sum_{j \in I} P_{i j}^{m}<n-1,
$$

so

$$
e_{i}\left(\bar{P}_{i}\right)=\lim _{m \rightarrow \infty}(1 / m) e_{i}^{m}\left(P^{m}\right) \leq 0
$$

Since $e_{i}\left(\bar{P}_{i}\right)$ satisfies limited liability, it follows that $e_{i}\left(\bar{P}_{i}\right)=0$.

We conclude that the matrix $\bar{P}$ is a clearing payment matrix in the sense of Definition 6.1 , so $e(\bar{P})=e^{*}$, and therefore

$$
\lim _{m \rightarrow \infty} \frac{1}{m} \cdot e^{m}\left(P^{m}\right)=e(\bar{P})=e^{*}
$$

A decentralized clearing process in the spirit of Definition 5.3 can also be defined in the divisible setup. We show by means of an example that in the divisible setup, convergence of a decentralized clearing process might require infinitely many iterations even if in every Step 2 of the process the highest payment vector consistent with limited liability is selected.

Example 6.3. As in Example 3.6, we consider a financial network $(z, L, d)$ with three agents $I=\{1,2,3\}$ and endowments and liabilities as presented in Table 8, but now do not assume a smallest unit of account, so have proportional division rules instead of proportional bankruptcy rules. The unique clearing payment matrix and the resulting asset and equity values are presented in Table 8 as well.

\begin{tabular}{c|ccc|ccc|c|c}
$z$ & \multicolumn{3}{|c|}{$L$} & & $P$ & $a(P)$ & $e(P)$ \\
\hline 1 & 0 & 2 & 2 & 0 & 1 & 1 & 2 & 0 \\
1 & 2 & 2 & 0 & 1 & 1 & 0 & 2 & 0 \\
1 & 0 & 0 & 0 & 0 & 0 & 0 & 3 & 3
\end{tabular}

Table 8: The financial network and the unique clearing payment matrix in Example 6.3, when using the proportional division rule.

We study a decentralized clearing process and start with the situation with agents making no transfers, $P^{1}=0^{I \times I}$. Under $P^{1}$, both agents 1 and 2 are eligible to be selected, 
since both of them have positive assets and positive liabilities. Assume the liquidator starts with agent 1 and requires him to make the maximal payment vector satisfying limited liability, $d_{1}\left(a_{1}\left(P^{1}\right)\right)=(0,1 / 2,1 / 2)$. At $P^{2}$ only agent 2 is eligible and the maximal payment vector satisfying limited liability is $d_{2}\left(a_{2}\left(P^{2}\right)\right)=(3 / 4,0,3 / 4)$. Proceeding in this way, we obtain the sequence of payment matrices as presented in Table 9 . Agents 1 and 2 are selected in an alternating fashion with their maximal payment vector consistent with limited liability. The process takes infinitely many iterations, so does never stop.

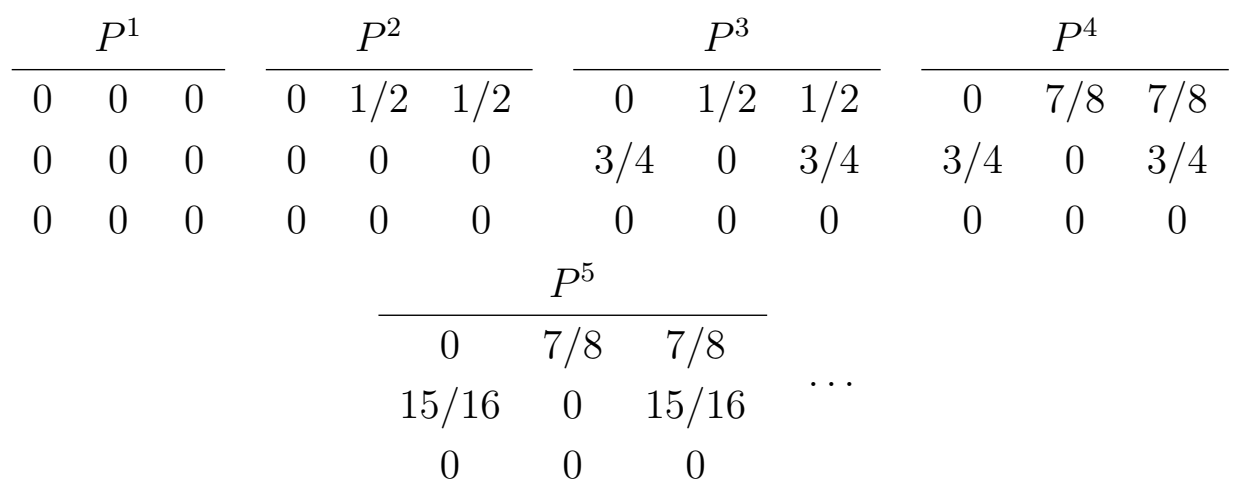

Table 9: The total payments in iterations 1, 2, 3, 4, and 5 in Example 6.3.

\section{Conclusion}

Motivated by a large literature on contagion in financial networks, we study bankruptcy problems in a network environment, thereby generalizing the large literature on bankruptcy problems that consider the division of a single estate among multiple claimants. An important difference with the case of a single estate is that in a network environment, the value of the estate is endogenous as it depends on the extent to which other agents pay their liabilities.

Unlike the large literature on systemic risk, which invariably has focused on proportional rules, we allow for general bankruptcy rules. Moreover, we do not study the perfectly divisible case, but instead assume that there is a smallest unit of account. Apart from the already mentioned financial applications, other examples where our model applies are for instance international student exchange networks and job processing by a network of servers.

We define the notion of a clearing payment matrix for our discrete setup as a payment matrix that satisfies feasibility, limited liability, and priority of creditors. We show that such payment matrices exist and that they constitute a complete lattice, so in particular there is a least and a greatest clearing payment matrix. Contrary to the divisible case, it is not the case that all payment matrices induce the same value of equity. It therefore matters 
which payment matrix is being used. We do produce bounds on the maximal differences in equity values that can result from using different clearing payment matrices.

The systemic risk literature on financial networks has considered a number of centralized procedures to find a clearing payment matrix and the emphasis has been on finding the greatest clearing payment matrix. The centralized procedures assume a great amount of coordination and information that is typically not available. In this paper we study decentralized processes to select agents and force them to liquidate their assets. We require that each iteration in such a process satisfies limited liability. The required payments can therefore be implemented at every step. We find that for a large class of decentralized processes, there is convergence to the least clearing payment matrix in a finite number of iterations. We argue that when the unit of account is sufficiently small, which would be the case in most financial applications, the final values of equity as determined by any decentralized process are essentially the same as the ones determined by a centralized procedure.

\section{References}

Acemoglu, Daron, Asuman Ozdaglar, Alireza Tahbaz-Salehi. 2015. Systemic risk and stability in financial networks. American Economic Review 105(2) 564-608. doi: 10.1257 /aer.20130456.

Bjørndal, Endre, Kurt Jörnsten. 2009. Flow sharing and bankruptcy games. International Journal of Game Theory 39(1-2) 11-28. doi:10.1007/s00182-009-0174-5.

Brown, J. Randall. 1979. The sharing problem. Operations Research 27 324-340.

Capponi, Agostino, Peng-chu Chen, David D Yao. 2015. Liability Concentration and Systemic Losses in Financial Networks. Operations Research (November) 1-33.

Chen, Chen, Garud Iyengar, Ciamac C. Moallemi. 2013. An axiomatic approach to systemic risk. Management Science 59(6) 1373-1388. doi:10.1287/mnsc.1120.1631.

Chen, Siwei. 2015. Systematic favorability in claims problems with indivisibilities. Social Choice and Welfare 44 283-300. doi:10.1007/s00355-014-0828-5.

Cifuentes, Rodrigo, Gianluigi Ferrucci, Hyun Song Shin. 2005. Liquidity risk and contagion. Journal of the European Economic Association 3(2-3) 556-566.

Demange, Gabrielle. 2015. Contagion in financial networks: a threat index. Working Paper $1-36$. 
Dur, Umut Mert, M Utku Ünver. 2015. Two-Sided Matching via Balanced Exchange: Tuition and Worker Exchanges. Working paper 1-52.

Eisenberg, Larry, TH Noe. 2001. Systemic risk in financial systems. Management Science $47236-249$.

Elliott, Matthew, Benjamin Golub, Matthew O. Jackson. 2014. Financial networks and contagion. American Economic Review 104(10) 3115-53. doi:10.1257/aer.104.10.3115.

Elsinger, Helmut, Alfred Lehar, Martin Summer. 2006. Risk Assessment for Banking Systems. Management Science, 52(9) 1301-1314.

Gai, Prasanna, Sujit Kapadia. 2010. Contagion in financial networks. Proceedings of the Royal Society of London A: Mathematical, Physical and Engineering Sciences 466 2401-2423. doi:10.1098/rspa.2009.0410.

Glasserman, Paul, H. Peyton Young. 2015. How likely is contagion in financial networks? Journal of Banking and Finance 50 383-399. doi:10.1016/j.jbankfin.2014.02.006.

Groote Schaarsberg, Mirjam, Hans Reijnierse, Peter Borm. 2013. On Solving Liability Problems. (CentER Discussion Paper; Vol. 2013-033). Tilburg: Econometrics. 1-26.

Herrero, Carmen, Ricardo Martínez. 2008. Balanced allocation methods for claims problems with indivisibilities. Social Choice and Welfare 30(4) 603-617. doi:10.1007/s00355007-0262-z.

Kaminski, Marek M. 2000. 'Hydraulic' rationing. Mathematical Social Sciences 40 131155.

Moulin, Hervé. 2000. Priority Rules and Other Asymmetric Rationing Methods. Econometrica 68 643-684.

Moulin, Hervé, Jay Sethuraman. 2013. The bipartite rationing problem. Operations Research 61(5) 1087-1100. doi:10.1287/opre.2013.1199.

Moulin, Hervé, Richard Stong. 2002. Fair Queuing and Other Probabilistic Allocation Methods. Mathematics of Operations Research 27(1) 1-30. doi:10.1287/moor.27.1.1.336.

O'Neill, Barry. 1982. A problem of rights arbitration from the Talmud. Mathematical Social Sciences 2(4) 345-371. doi:10.1016/0165-4896(82)90029-4.

Rogers, L. C. G., L. A. M. Veraart. 2013. Failure and rescue in an interbank network. Management Science 59(4) pp. 882-898. 
Shin, Hyun Song. 2008. Risk and liquidity in a system context. Journal of Financial Intermediation 17(3) 315-329. doi:10.1016/j.jfi.2008.02.003.

Tarski, A. 1955. A lattice-theoretical fixpoint theorem and its applications. Pacific Journal of Mathematics 5 285-309.

Thomson, William. 2003. Axiomatic and game-theoretic analysis of bankruptcy and taxation problems: A survey. Mathematical Social Sciences 45 249-297.

Thomson, William. 2013. Game-theoretic analysis of bankruptcy and taxation problems: Recent advances. International Game Theory Review 15(03) 1-14. doi: 10.1142/S0219198913400185.

Thomson, William. 2015. Axiomatic and game-theoretic analysis of bankruptcy and taxation problems: An update. Mathematical Social Sciences 74 41-59.

Young, H. P. 1994. Equity: Theory and Practice. Princeton University Press. 